\title{
CULTIVANDO UN JARDÍN DE NOMBRES EN LOS BOSQUES \\ EN MINIATURA DEL CABO DE HORNOS: EXTENSIÓN DE LA CONSERVACIÓN BIOCULTURAL Y LA ÉTICA A SERES VIVOS POCO PERCIBIDOS
}

\author{
LILY LEWISa,b, CAROLINE GOTTSCHALK-DRUSCHKEc, CAMILA SALDÍAS', ROY \\ MACKENZIEE ${ }^{a, d}$, JAVIERA MALEBRÁNa,e, BERNARD GOFFINET ${ }^{a, f}$, RICARDO ROZZI ${ }^{\mathrm{a}, \mathrm{s}}$
}

\section{RESUMEN}

Las briófitas (musgos, hepáticas y antocerotes) y los líquenes han sido subvalorados en los programas de conservación y educación ambiental, y por la cultura moderna en general. Tanto es así, que la mayoría de las briofitas y líquenes carecen de un nombre común. Aquí presentamos una nueva metodología y actividad para fomentar una comprensión ecológica de la biodiversidad, como también de la conservación y la ética biocultural, que incluya a seres vivos pequeños y poco percibidos; tales como las briófitas. Si algo no tiene nombre, entonces no existe en el ámbito cultural. Si algo se nombra, entonces sí existe en la esfera cultural; además, su existencia queda decisivamente influida por su nombre. En el extremo sur del continente americano, la Reserva de la Biosfera Cabo de Hornos de la UNESCO en Chile protege un "hotspot" o centro mundial de diversidad de briofitas. Aquí el equipo de investigación en el Parque Etnobotánico Omora ha desarrollado una innovadora actividad educativa y de ecoturismo para apreciar las briofitas: Cultivando un Jardin de Nombres. Esta actividad se ha desarrollado bajo la aproximación metodológica de la Filosofía Ambiental de Campo (FILAC), que anima a estudiantes y visitantes a observar y apreciar tanto biofísica como culturalmente (incluyendo la dimensión simbólico-lingüística) la existencia de las briófitas y líquenes, sus hábitos de vida y sus hábitats. Los participantes son invitados a observar, dibujar y crear nombres para las briofitas y líquenes

a Parque Etnobotánico Omora, Instituto de Ecología y Biodiversidad (IEB-Chile) y Universidad de Magallanes. Puerto Williams, Provincia Antártica Chilena, Chile. $\measuredangle$ LilyRLewis@gmail.com

b Department of Biology, University of Florida, PO Box 118525 Gainesville FL 3261, USA.

c Department of English, University of Wisconsin-Madison, 600 N. Park St. Madison, WI 53706, USA

d Departamento de Genética Molecular y Microbiología, P. Universidad Católica de Chile, Portugal 49, CP 8330025, Santiago, Chile.

e Estudiante de Biología con mención en Medio Ambiente, Facultad de Ciencias, Universidad de Chile, Las Palmeras 3425, Nuñoa, Santiago, Chile.

f Department of Ecology \& Evolutionary Biology, University of Connecticut, 75 North Eagleville road, Storrs CT 06269-3043, USA.

s Sub-Antarctic Biocultural Conservation Program, Department of Philosophy and Religion \& Department of Biological Sciences, University of North Texas, 1704 West Mulberry, Denton, TX 76201, USA 
utilizando: (i) una lupa de mano para amplificar las características biofísicas de las plantas pequeñas y (ii) los lentes conceptuales de la ética biocultural para amplificar la comprensión acerca de cómo interpretar y respetar el mundo natural. A través de esta actividad, los participantes se conectan a seres vivos que eran antes poco percibidos y comienzan a visualizar, valorar y cuidar una realidad biofísica y cultural que es diversa, hermosa, y cumple funciones ecológicas que son esenciales para la integridad de los ecosistemas y el bienestar humano. Cultivando un Jardín de Nombres promueve un cambio de perspectiva científica y ética para incluir a grupos de seres vivos poco percibidos en las metas de conservación y educación ambiental.

PALABRAS CLAVE: Briofitas, educación, ética biocultural, filosofía ambiental de campo, líquenes.

\section{CULTIVATING A GARDEN OF NAMES IN THE CAPE HORN MINIATURE FORESTS: EXTENDING BIOCULTURAL CONSERVATION AND ETHICS TO LITTLE PERCEIVED LIVING BEINGS}

\section{ABSTRACT}

Bryophytes (mosses, liverworts, and hornworts) and lichens have been undervalued in conservation and environmental education programs, and by modern culture in general. So much so, that most bryophytes and lichens lack a common name. We present a new methodology and activity to foster an ecological understanding of biodiversity, as well as of biocultural conservation and ethics, which includes little, under-perceived, living-beings --such as bryophytes. If something has no name, it does not exist in the cultural realm. If something is named, then it exists in the cultural sphere; additionally, its existence is decisively influenced by its name. At the southern end of the Americas, the UNESCO Cape Horn Biosphere Reserve in Chile protects a world's biodiversity hotspot for bryophytes. Here, the research team at the Omora Ethnobotanical Park has developed an innovative educational and ecotourism activity to appreciate bryophytes: Cultivating a garden of names. This activity has been developed with the methodological approach of Field Environmental Philosophy. It encourages students and park's visitors to engage physically as well as culturally (including the symbolic-linguistic dimension) with bryophytes and lichens, their life-habits and habitats. Park's visitors are invited to observe, draw, and create names for bryophytes and lichens by using: (i) a magnifying glass or hand-lens to amplify the biophysical features of small plants, and (ii) the conceptual lenses of the biocultural ethics to broaden their understanding about how to interpret and respect the natural world. Through this activity, visitors connect to living beings that were previously under-perceived, and they come to see, value and care for a biophysical reality that is diverse, beautiful, and performs ecological functions that are essential to ecosystem integrity and human well-being. Cultivating a garden of names fosters a change of scientific and ethical perspectives to include little-perceived groups of organisms into the goals of conservation and environmental education.

KEY WORDS: Bryophytes, biocultural ethics, education, field environmental philosophy, lichens.

\section{INTRODUCCIÓN}

La investigación y educación de las relaciones ecológicas y evolutivas puede tomar diversas direcciones, y en muchos casos estas disciplinas se realizan para guiar o informar acciones de conservación. La aproximación dominante en los distintos campos de las ciencias biológicas es la de enfocarse únicamente en la dimensión biofísica, a pesar de la gran necesidad de integrar la ética ambiental en el contexto del rápido cambio socioambiental (Leopold, 2004; Rozzi, 2015a). El enfoque biofísico de la biología ecológica y evolutiva (BEE) es insuficiente por sí mismo para abordar 
completamente las crisis ambientales presentes y futuras a escala local o global, puesto que no está dirigido a los valores que ya se encuentran enraizados en las causas últimas ${ }^{1}$ del rápido cambio socio-ambiental global. Enfocarse únicamente en las dimensiones biofísicas no promueve cambios en las acciones de las personas puesto que no inspira respuestas emocionales $\mathrm{O}$ afectivas $\mathrm{O}$, más importante aún, una extensión de la ética a los seres no-humanos (Dickinson, 2013). En vista de la creciente complejidad de las problemáticas ambientales, económicas y sociales, Arne Naess (1973) dice que "necesitamos más que sólo ciencia". Otros pensadores coinciden con Naess, y han propuesto que la investigación y educación de la BEE debería ampliarse y añadir una orientación de lo cultural y lo ético, incluyendo prácticas de la filosofía y de la retórica, particularmente si se procura generar cambios en las relaciones entre seres humanos y no-humanos que motiven los esfuerzos de conservación biocultural ${ }^{2}$ (Rozzi et al. 2008a, 2012a; Drushke \& McGreavy, 2016).

\section{FILOSOFIA AMBIENTAL DE CAMPO: UN MARCO PARA INTEGRAR LA ÉTICA AMBIENTAL Y LA BIOLOGÍA ECÓLOGICA Y EVOLUTIVA EN LA CONSERVACIÓN}

En el extremo austral de América, el equipo de investigación del Parque Etnobotánico Omora (Parque Omora) ha desarrollado la Filosofía Ambiental de Campo (FILAC), una metodología para integrar las dimensiones biofísicas y culturales de la conservación de la biodiversidad. La FILAC provee una metodología de cuatro pasos que integra la investigación en ética ambiental (dimensión cultural) y BEE (dimensión biofísica) para desarrollar actividades innovadoras de educación y conservación biocultural (Rozzi et al. 2008a,b, 2010, 2012a). Los cuatro pasos están conectados fluidamente y no necesariamente requieren ser implementados en el orden presentado (Fig. 1).

1 Aquí nos referimos a causas últimas en yuxtaposición a las causas próximas. Se hace distinción entre "últimas" como aquellas que originan un problema, mientras que las "próximas" son derivadas de la original o sus síntomas directos. En general, la ética abarca las causas últimas, mientras que la BEE y sus ciencias afines están dirigidas a las causas próximas de los problemas socio-ambientales.
Estos incluyen: 1) investigación BEE y filosófica interdisciplinaria, 2) comunicación poética a través de la narrativa y creación de metáforas, 3) diseño de experiencias en terreno guiadas con una orientación ecológica y ética, y 4) la implementación de áreas de conservación in-situ (Rozzi et al. 2010).

La metodología de la FILAC permite abordar una segunda limitación central en la investigación actual de la BEE: un marcado sesgo hacia las plantas y animales de gran tamaño (Bonnet et al. 2002; Rozzi et al. 2008b; Hall et al. 2011; Small, 2012). Este sesgo taxonómico afecta también los programas de educación y de conservación ambiental: las pequeñas briófitas (musgos, hepáticas y antocerotes) y líquenes, han sido pasados por alto en la cultura moderna. Esto se refleja y perpetua en la falta de nombres comunes para la mayoría de las briófitas y líquenes. La ausencia de nombres comunes para estos organismos los excluye del imaginario de la mayoría de los conservacionistas y de la sociedad en general. Sin nombre, un ser no existe en el ámbito cultural. Un nombre representa una conexión biocultural, trayendo ese ser vivo a la existencia en la esfera cultural, a la vez que influye decisivamente la percepción de lo nombrado (Rozzi, 2015b, pp. 88-89).

El sesgo negativo sobre las briófitas y líquenes se vuelve particularmente problemático a altas latitudes, puesto que las briófitas dominan muchos tipos vegetacionales en las regiones subpolares y polares. A diferencia de otros grupos de organismos, las briófitas aumentan su diversidad en cuanto a riqueza de especies al aumentar la latitud (Mateo et al. 2016; Rozzi et al. 2008b). En algunos casos, como en la Reserva de la Biosfera Cabo de Hornos en Chile (Rozzi et al. 2008b), Antártica (Ochyra et al. 2008), y la Isla Noruega Ártica de Svalbard (Daniëls et al. 2013), las briófitas sobrepasan en número a otros grupos de plantas. Además de contribuir significativamente a la riqueza de especies, las briófitas sustentan diversas comunidades "en miniatura" (Lindo \&

2 El marco ético biocultural descrito por Rozzi (2015a; p. 116, fig. 9.1) llama a la integración de las dimensiones biofísicas, culturales, e institucionales de la realidad. Como parte de esta integración, se requiere una valoración del vital enlace entre co-habitantes (humanos y no-humanos) y sus hábitos de vida en relación a sus hábitats en los esfuerzos de conservación 

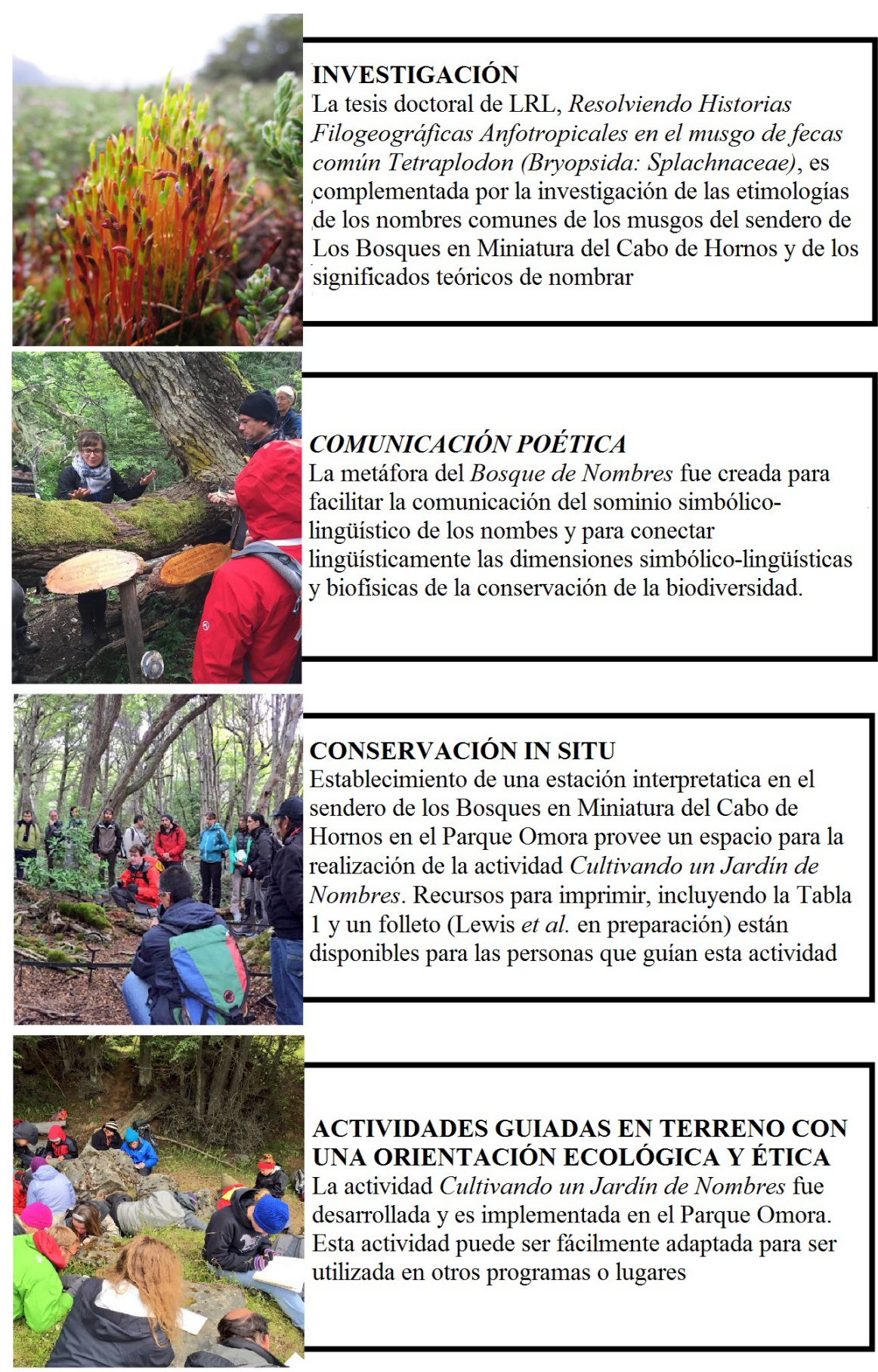

Fig. 1. La Metodología de los cuatro pasos de la FILAC para la integración de las ciencias ecológicas y evolutivas y la ética biocultural en la conservación que se ha empleado para la creación de la actividad Cultivando un Jardín de Nombres.

Las interacciones entre los cuatro pasos son multidireccionales. Esta figura es una adaptación y es complementaria al Panel 1 en Rozzi et al 2008a, p. 135. 
Gonzalez, 2010; Goffinet et al. 2012) y juegan un rol significativo en las reservas de carbono globales, tanto directamente (Adams et al. 1990; Belyea \& Malmer, 2004) como a través de las interacciones ecológicas que mantienen con microorganismos del suelo (Lindo et al. 2013).

En este artículo abordamos dos limitaciones: (1) la invisibilidad de las briófitas y líquenes en programas de conservación, educación e investigación; y (2) la falta de integración entre la BEE y la ética ambiental. Para superar la primera limitación, hemos creado una actividad novedosa llamada Cultivando un Jardín de Nombres. Esta actividad fue desarrollada como parte de la metodología de cuatro pasos de la FILAC, que aborda la segunda limitación. Primeramente describimos la actividad Cultivando un Jardín de Nombres y sus contribuciones al Ecoturismo con Lupa, analizando cómo funciona, su base teórica e implicaciones deseadas de esta actividad. Luego, describimos la aplicación de la FILAC para la investigación briológica y las actividades de conservación en el Parque Omora que integran las dimensiones biofísicas y simbólico-lingüísticas de la biodiversidad.

\section{CULTIVANDO UN JARDÍN DE NOMBRES}

\section{Un complemento dinámico al Ecoturismo con Lupa}

Cultivando un Jardin de Nombres introduce un complemento lúdico y atractivo a la FILAC inspirado en las actividades de Ecoturismo con Lupa en el Parque Omora (Goffinet et al. 2012; Rozzi et al. 2010, 2012b). Esta actividad guía a los visitantes a apreciar los atributos tanto culturales como biofísicos de las briófitas y líquenes, así como los hábitats donde crecen. La terminología de la FILAC se basa en el concepto central de la ética biocultural: la interrelación entre los hábitos de vida, las comunidades de co-habitantes y los hábitats donde ocurren. Las "3Hs" de la ética

3 La Eco-Región Magallánica Sub Antártica es un hotspot en diversidad de briófitas y líquenes, siendo el hogar de un $5 \%$ de la diversidad mundial de briófitas, mientras que sólo representa el 0,01\% del hábitat terrestre global (Rozzi et al. 2008b). Este descubrimiento jugó un rol importante en la creación de la Reserva de la Biosfera Cabo de Hornos, e biocultural son integradas por el Ecoturismo con Lupa, y su actividad asociada Cultivando un Jardín de Nombres, que promueven un hábito de participación con diversos co-habitantes humanos y no-humanos (por ejemplo, briófitas y líquenes, así como otras plantas pequeñas vasculares) en hábitats particulares, de modo de conectarse más profundamente con ellos y aprender sobre las relaciones que entablan. Cada uno de estos componentes centrales de la ética biocultural (hábitos, co-habitantes y hábitats) comprenden dimensiones biofísicas, simbólico-lingüísticas e institucional-social-políticas (Rozzi, 2015a).

Como parte del Ecoturismo con Lupa, al ingresar al Parque Omora los visitantes recorren los senderos interpretativos de los Bosques en Miniatura del Cabo de Hornos. Con una lupa en la mano son motivados a mirar de cerca la sorprendente variedad de briófitas y líquenes y los microhábitats donde crecen ${ }^{3}$. Al incentivar a los visitantes a interactuar físicamente con su hábitat - arrodillándose, recostándose, trepando, acercándose y ajustando sus ojos y sus manos a la posición de la lupa en relación a un determinado parche de musgos, hepáticas, antocerotes o líquenes - los visitantes son guiados a encuentros directos con los bosques en miniatura. Dado que la actividad depende de una pequeña lupa, promueve tanto una cercanía (ya que los observadores se tienden junto a briófitas y líquenes) como una distancia (ya que los visitantes interponen una lupa para observar las briófitas y líquenes). Así, la actividad promueve un escrutinio y una relación con estos cohabitantes biofísicos.

A lo largo de los senderos hay estructuras metálicas con forma de lupa (incluyendo etiquetas con nombres científicos) dispuestas alrededor de grupos particulares de briófitas y líquenes que ayudan a los visitantes a apreciar la gran diversidad de los bosques en miniatura. Complementariamente, un guía invita a los visitantes a observar a través de "lentes estéticos, económicos, éticos y bioculturales" para valorar las briófitas y líquenes.

inspiró la creación del Ecoturismo con Lupa y el Sendero de los Bosques en Miniatura del Cabo de Hornos en el Parque Omora y sirve como punto de enfoque biofísico para las actividades mencionadas en este artículo (Goffinet et al. 2012; Rozzi et al. 2008b; 2012b). 
De manera interactiva, los visitantes son invitados a considerar un lenguaje metafórico y de uso diario, y sus prácticas (sus "lentes conceptuales") a través de los cuales ellos ven y valoran plantas y biodiversidad en general. También se preguntan cómo estos lentes conceptuales dan forma a sus hábitos de vida y a sus relaciones con la diversidad de seres vivos y co-habitantes. Para muchos, esto representa su primer encuentro consciente con briófitas y líquenes.

\section{Cultivando un Jardin de Nombres}

La actividad Cultivando un Jardin de Nombres tiene un gran potencial como herramienta de educación ambiental para todos los niveles de enseñanza (preescolar, escolar y universitaria) que estimula desde una edad temprana a explorar, jugar, observar, descubrir e inventar nombres y también historias de vida, que estimulan una relación ética con el mundo poco percibido de las briófitas y otros organismos pequeños. Es una actividad educativa integral que combina diferentes asignaturas $y$ actividades (las ciencias, las artes, el senderismo), motivando un aprendizaje más amplio que una apreciación puramente científica de la naturaleza y de nuestra relación con ella.

Desde el año 2001, estudiantes de Chile, Estados Unidos y otros países han participado en el curso anual de FILAC, (también llamado Conservación Biocultural de Campo) en el Parque Omora. En 2015 y 2016 invitamos a los estudiantes a tomar una larga pausa contemplativa (sensu Dickinson, 2011) para dibujar y crear nombres para briófitas y líquenes. Luego de una breve discusión introductoria sobre la importancia de las briófitas y líquenes en la Reserva de la Biosfera Cabo de Hornos (Rozzi et al. 2008b; Goffinet et al. 2012), los estudiantes fueron instados a seleccionar plantas para dibujar y nombrar. Se motivó a los estudiantes a usar el dibujo como una herramienta de observación, interpretación y comprensión. Esta experiencia se ha realizado también con estudiantes del liceo Donald Mc Intyre Griffiths de Puerto Williams (Fig. 2) (Rozzi et al. 2012). El dibujo es un componente importante de la actividad "Cultivando un Jardín de Nombres": requiere que el estudiante se detenga y observe en detalle las características de las plantas que dibuja, permitiendo percibir el bosque desde otra perspectiva (Dickinson, 2011).

La Fig. 2 ilustra algunos ejemplos de dibujos y nombres creados por los estudiantes del Taller Omora en el Liceo Donald McIntyre de Puerto Williams. Durante el taller "Comparando árboles y musgos", en octubre 2014 niños y niñas de tercero básico observaron y dibujaron árboles y musgos, y escribieron una lista de similitudes y diferencias entre ambos grupos de plantas. Los nombres dados por los estudiantes a los musgos incluyeron principalmente analogías con otros organismos (gusanos, cactus, insectos), artefactos (vela, pistola), texturas (peludo), hábitos (creciente) o proyecciones antropomórficas de personalidad (loco). El pensamiento analógico amplía el marco conceptual de la ciencia (dominado hoy por el método hipotético-deductivo) y es un elemento esencial de la aproximación metodológica de la FILAC. Para facilitar la atención en el musgo observado y desde ahí construir los nombres analógicos, los estudiantes pegaron una muestra del musgo dibujado en la parte superior de la cartulina. En otros talleres se ha privilegiado la observación del musgo en su hábitat natural, respetando la vida del musgo y comprendiendo sus hábitos de vida en interrelaciones con los co-habitantes (otros musgos, insectos, árboles, etc.) de los organismos en los "bosques en miniatura". Fue notable la espontaneidad y la sorpresa que les causó descubrir y nombrar a los musgos, seres que normalmente eran invisibles para ellos. Los resultados de estas y otras indagaciones son habitualmente presentados en congresos científicos escolares, donde los estudiantes del Liceo de Puerto Williams han recibido premios de EXPLORA-CONICYT a nivel regional y nacional.

La actividad Cultivando un jardín de nombres también se ha desarrollado a nivel preescolar. Estudiantes en práctica de la Carrera de Educación Parvularia de la Universidad de Magallanes apoyadas por el equipo de educación del Parque Omora, han realizado talleres centrados en el aprendizaje al aire libre enfocados en el encuentro directo con los bosques en miniatura. En este nivel se incentiva que los preescolares toquen, huelan, observen, dibujen y nombren, reforzando esta experiencia con obras de teatro. En dinámicas de juego se motiva un pensamiento 


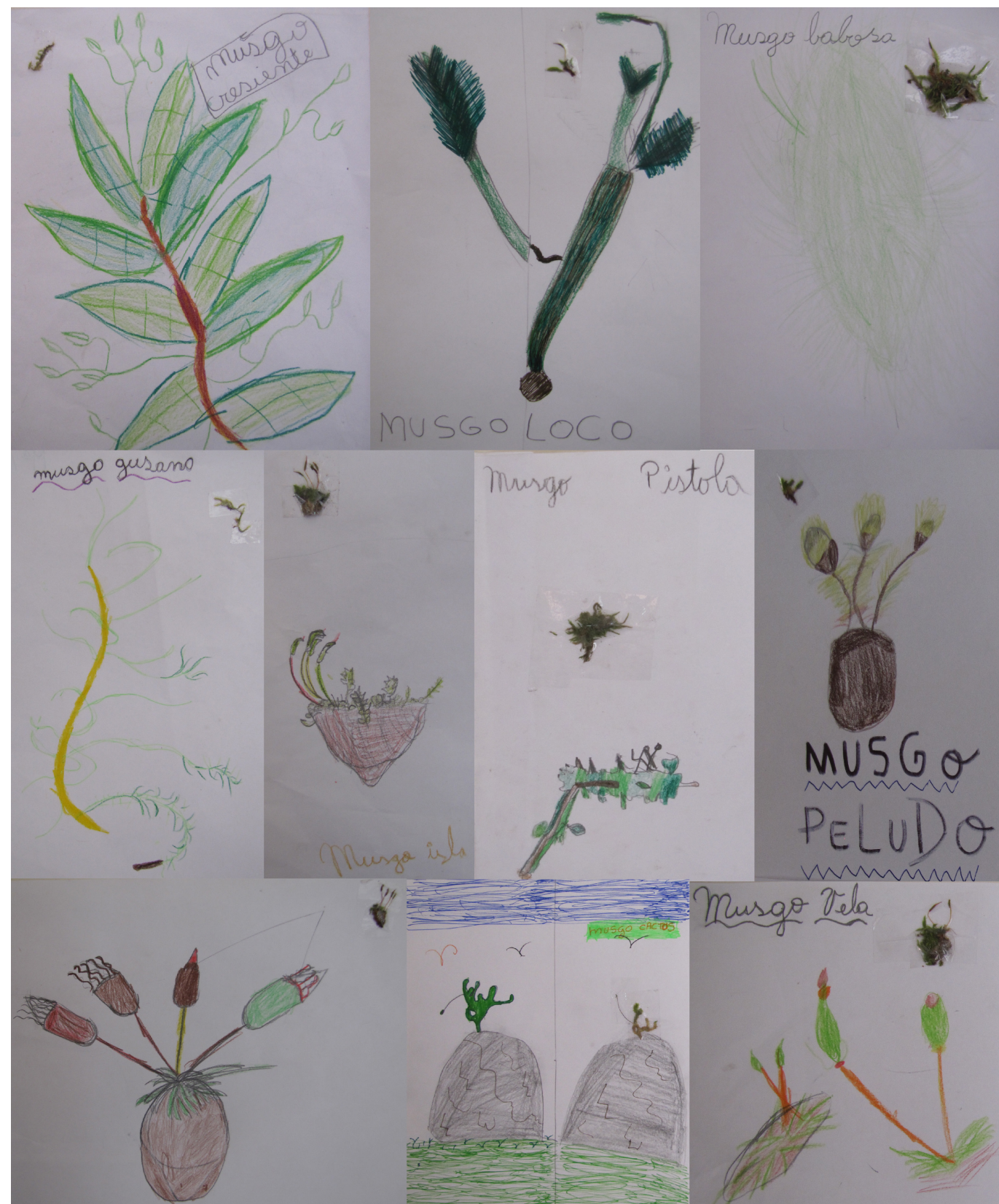

Fig. 2. Selección de diez ilustraciones y nombres de musgos creados por estudiantes de Tercero Básico del Taller Omora en el Liceo Donald McIntyre de Puerto Williams en octubre 2014 bajo la dirección de la profesora María Eugenia Urrutia y la bióloga Camila Saldías. Nótense las pequeñas muestras de musgos adheridas en las cartulinas de cada dibujo.

analógico lúdico invitando a los preescolares a "ser como musgos", formando grupos donde los niños se ubican muy cerca entre ellos, quedándose quietos como si fueran parte de un cojín verde. Este ejercicio también funciona muy bien cuando los pequeños "son como árboles", en el que estiran sus brazos como si fueran las ramas del árbol, respiran y crecen guardando silencio, absorbiendo la luz solar, o bien cayendo al suelo por el empuje del viento. De esta manera se trasciende a la actividad 
de nombrar musgos, enfatizando la conciencia temprana sobre co-habitar con la comunidad de seres, pequeños y grandes.

Los estudiantes del curso anual FILAC se reúnen después de la aplicación de la actividad para explorar grupalmente el "bosque simbólicolingüístico", aquel representado en sus dibujos y en los nombres que habían creado para los sujetos de sus dibujos. Luego que los estudiantes se ofrecieran voluntariamente a presentar el líquen o briófita que habían dibujado o nombrado, los nombres conocidos - científico o común - fueron comparados con los nombres nuevos, generando una discusión desde una perspectiva biocultural. Si los nombres o etimologías no eran conocidos, el grupo era alentado a enfocar el ejercicio de interpretación analizando y comparando los nombres creados.

A menudo varios participantes se enfocan en diferentes parches de la misma especie, dependiendo de la especie dominante del lugar donde se realiza la actividad. Cerca de la entrada del Parque Omora, los líquenes del género Cladonia son abundantes y usualmente atraen la mayor atención de los visitantes con su característica forma tridimensional erguida. En una ocasión, un tercio de los participantes eligió dibujar Cladonia. Durante la discusión descubrimos que cada uno de ellos había inventado un nombre distintivo basado en aquello que el líquen les recordaba, incluyendo tacitas de té, un soporte de bola ("tee") de golf, dulces esparcidos en el pasto, mientras que otros estudiantes enfatizaron con sus nombres la textura rugosa de las superficies de las Cladonia.

Un musgo que crece en las rocas a la entrada del Parque Omora es Orthotrichium rupestre. El nombre científico deriva del griego Orthotrichium [(ortho (erguido) + trich (pelo)] se refiere a las pilosidades erguidas en una estructura llamada caliptra, y el latín rupestre [rupes (roca)] refiriendose al sustrato preferido del musgo (Tabla $1)$. Este musgo crece en cojinetes de pedúnculos erguidos sobre la roca, lo cual recordó a uno de los participantes el mirar una habitación desde arriba, llena de gente bailando. Comúnmente, los participantes asocian musgos a estrellas, notando

4 Los musgos tienen una arquitectura modular, con todas las células derivadas de una única célula apical. Mientras la célula apical se divide y produce células hijas, va girando a intervalos regulares, lo que resulta en una disposición en la disposición en espiral con un claro alineamiento de las hojas alrededor del tallo 4 .

Esta selección de etimologías destaca el uso de la ecología y el hábitat, hace referencia a mitologías griegas, compara objetos familiares en las especies del hemisferio norte, y los nombres de científicos occidentales en los nombres de algunos musgos. Las etimologías fueron interpretadas a partir de las raíces griegas y latinas de las palabras que se enumeran en Webster (2002). Las raíces de las palabras fueron interpretadas para cada especie en base a la descripción de la morfología de ellas y de observaciones de campo, salvo que se indique lo contrario. Los nombres científicos se componen de dos partes, la primera palabra define el género al que pertenece la especie, y la segunda palabra, o epíteto específico, es única para esa especie en particular dentro del género. Los nombres abreviados de las personas que nombraron las especies se encuentran a continuación del nombre científico, con el nombre del autor que describió originalmente la especie; para aquellas especies cuya definición dentro de un género particular ha cambiado (es decir, el género original y epíteto específico ya no se aceptan dentro de la comunidad científica), el nombre a continuación del paréntesis corresponde al nombre del autor que define a la especie en el género actual. Algunos géneros tienen varias especies tratadas aquí. En estos casos, se abrevia la primera parte del nombre (es decir, Syntrichia saxicola $=S$. saxicola). Al comparar los nombres científicos con los creados por los participantes en la actividad Cultivando un Jardin de Nombres, puede ser importante tener en cuenta que algunas de las características mencionadas en los nombres científicos son microscópicas, y no serán visibles para alguien que observa con una lupa, pero en cambio ofrecen ejemplos de características biofísicas del sujeto que son destacadas en un nombre. Para fotos y descripciones más detalladas de las especies tratadas aquí, ver Goffinet et al. (2012).

La actividad Cultivando un jardin de nombres logra su propósito al conducir a los particpantes a observar las briófitas y líquenes tanto

espiral de las hojas. En muchos casos esta disposición en espiral de las hojas genera una forma de estrella cuando se le mira desde arriba. 
Tabla 1. Etimologías interpretadas de los nombres científicos de una selección de especies de musgos que se encuentran comúnmente a lo largo del sendero de los Bosques en Miniatura del Cabo de Hornos. Para la interpretación de la etimología se utilizaron Webster (2002), Dixon (1904), Goffinet et al. (2012) y otras fuentes.

\begin{tabular}{l} 
Nombre Científico \\
\hline Acrocladium \\
auriculatum (Mont.) \\
Mitt. \\
Bartramia Hedw. \\
B. halleriana \\
(B. mossmaniana) \\
Hedw. \\
B. patens Brid. \\
Catagonium nitens \\
(Brid.) Cardot
\end{tabular}

Interpretación etimológica

El nombre genérico Acrocladium, deriva de los términos griegos acro (punta), clad (rama) e ium (pequeña), y se refiere a las pequeñas puntas agudas de las ramas de este musgo. El nombre especifico auriculatum, deriva del Latin auricul ("auricula" de una oreja o corazón) y tum (aumentar), y describe la forma acorazonada de las hojas de este musgo.

El nombre genérico Bartramia hace honor al botánico y colono Norteamericano John Bartram (1699-1777).

El nombre específico halleriana hace honor al científico y poeta suizo Albrecht von Haller (17081777).

El nombre específico patens hace referencia a la forma de propagación de este musgo, más probablemente al hábito de las hojas.

El nombre genérico Catagonium deriva de los términos griegos cata (hacia abajo) y goni (ángulo o semilla) y describe el ángulo hacia abajo en el que crecen los tallos de este musgo y la posible orientación hacia abajo de las cápsulas que contienen las esporas. El nombre específico Nitens proviene de los términos latinos nitid (brillante, guepo) y se refiere a la apariencia brillante o lustrosa de este musgo.

El nombre genérico Ceratodon deriva de los términos griegos keratos (cuerno) y odon (diente), y alude al anillo de dientes en la boca de la cápsula que contiene las esporas, los cuales quizá se pensaba, se asemejaban a cuernos. El nombre específico purpureus proviene del latín purpure (morado), que describe el color café-rojizo a morado de este musgo.

El nombre genérico Cinclidium deriva de la palabra griega kinklid (entramado), y probablemente alude al anillo interno de dientes en la boca de la cápsula que contiene las esporas, que forma una

Cinclidium stygium Sw. cúpula afirmada por segmentos que asemejan pilares. El nombre específico stygium deriva del griego styg (odio) y podría referirse al río y la ciénega del inframundo Styx, de la mitología griega. Esta referencia probablemente alude a que este musgo usualmente cohabita con helechos.

El nombre genérico Dicranoloma deriva de los términos griegos dicran (dos puntas) y loma

Dicranoloma (Renauld) (borde), y es derivado del nombre de un musgo similar, Dicranum, comunmente encontrado en Renauld el Hermisferio Norte, que tiende a tener ramas bífidas. Loma o "borde" hace alución a las células lineares de paredes gruesas, que bordean las hojas de Dicranoloma.

D. chilense (De Not.) Ochyra \& Matteri

El nombre específico chilense refleja que esta especie es encontrada únicamente en el sur de Chile y muy ocasionalmente en Argentina.

D. robustum (Hook. f. \& El nombre específico robustum deriva del latín robust (robusto), y probablemente se refiere a la Wilson) Paris apariencia general de este conspicuo musgo.

Funaria hygrometrica Hedw.

El nombre genérico Funaria se basa en el término latino funis (cuerda), y se refiere a la percepción del tallo del esporofito, o seta, que asemeja a una cuerda; lo cual también se refleja en el nombre común en inglés musgo-cuerda (cord-moss). El nombre específico hygrometrica se refiere al movimiento retorcido y rizado de la seta en respuesta a cambios de humedad.

Grimmia trichophylla Grev.

Hypnum Hedw.
El nombre genérico Grimmia hace honor al médico y botánico alemán Johann Friedrich Carl Grimm (1737-1821). El nombre específico trichophylla deriva de los términos griegos tricho (pelo) y phyllo (hoja)], describe la forma en que las hojas terminan en puntas que asemejan pelos.

El nombre genérico Hypnum deriva del término griego hypno (dormir; musgo). Hypnos (personificación griega del sueño)] puede hacer referencia al uso histórico de este y otros musgos como relleno de almohadas y cojines. 
(viene de pág. anterior)

\begin{tabular}{ll}
\hline Nombre Cientifico $\quad$ Interpretación etimológica \\
\hline
\end{tabular}

El nombre específico cupressiforme sugiere que este musgo se parece de alguna manera al ciprés

H. cupressiforme Hedw. (Cupressus), una conífera encontrada en regiones temperadas en el norte, y que es pariente de las secuoyas gigantes.

H. skottsbergii Ando

El nombre específico skottsbergii hace honor al botánico sueco Carl Skottsberg (1880-1963) que exploró la Antártica y la Patagonia.

Leptotheca

gaudichaudii Schwägr.

El nombre genérico Leptotheca proviene de los términos griegos lepto (fino, delgado) y theca (caja, taza, estuche), y describe la cápsula de esporas que es larga y angosta. El nombre específico gaudichaudii hace honor al botanista francés Charles Gaudichaud-Beaupré.

El nombre genérico Lepyrodon proviene de los términos griegos lepyr (concha o cáscara) y dom

Lepyrodon lagurus

(Hook.) Mitt.

(casa), y puede referirse a los esporofitos producidos en abundancia que usualmente se mantienen unidos al musgo mucho después de haberse dispersado las semillas. El nombre específico lagurus deriva de los términos griegos lagōs (liebre) y urus (que tiene cola), y probablemente se refiere a la idea de que las puntas de las ramas asemejan colas de conejo/liebre.

Philonotis vagans (Hook. f. \& Wilson) Mitt.

El nombre genérico Philonotis proviene de los términos griegos philos (amante) y notis (humedad), lo cual se traduce como "amante de la humedad", apuntando al hábito y hábitat del musgo, que puede ser encontrado en suelo húmedo o en rocas cerca del agua. El nombre específico vagans proviene del latín vagan (vagar), y posiblemente alude a la forma gentil en que los tallos de este musgo se inclinan hacia el suelo.

El nombre genérico Polytrichadelphus proviene de los términos en griego poly (muchos), trich (pelo) y adelphus (hermano), y se refiere a la cercana relación de este musgo con los del género Polytrichum, y a los muchos "pelos" de la caliptra, característica de ambos musgos. El nombre específico magellanicus hace referencia al explorador Hernando de Magallanes (Ferdinand Magellan) quien es considerado como el primer europeo en circunnavegar el mundo y en honor a quien fue nombrada la región de Magallanes.

Orthotrichum rupestre Schleich. ex Schwägr.

El nombre genérico Orthotrichum proviene de los términos griegos ortho (erguido) y trich (pelo), y se refiere a los pelos erguidos en la caliptra. El nombre específico ruprestre proviene del latín rupes (piedra), y hace referencia al sustrato en que crece este musgo.

El nombre genérico Syntrichia proviene de los términos griegos syn (juntos) y trich (pelo), y se

Syntrichia Brid.

S. saxicola (Cardot) R. H. Zander

S. anderssonii (Ångstr.) R. H. Zander

Tayloria mirabilis (Cardot) Broth. refiere a los dientes del peristoma con forma de pelos que están unidos en la base y que pueden ser observados con una lupa en la apertura de la cápsula que contiene las esporas.

El nombre genérico saxicola deriva de los términos en latín saxum, saxi (piedra) y cola (habitante), y se refiere al sustrato, donde crece este musgo.

El nombre específico anderssonii hace honor al profesor N.J. Andersson, quien colectó el material original.

El género Tayloria fue nombrado por Sir William J. Hooker (1785-1865) en honor al botánico inglés Thomas Taylor (1775-1848), quien trabajó estrechamente con Hooker para escribir "Muscologia Britannica" (1818), un importante recurso de los inicios de la briología. El nombre específico mirabilis proviene del latín mirab (maravilloso, impresionante, extraordinario), y se refiere a la percepción de esta especie como hermosa y extraordinaria.

El nombre genérico Tetraplodon deriva de los términos griegos tetrapl (cuádruple) y odon (diente), y alude al arreglo de los dientes en cuartetos en la apertura de la cápsula de esporas, los cuales

Tetraplodon fuegianus Besch. están unidos en grupos de cuatro cuando son jóvenes. El nombre específico fuegianus se refiere a la región fueguina donde este musgo fue descrito, y destaca la novedad geográfica de su ocurrencia en la punta más austral de América, muy lejos de la especie común del norte T. mnioides.

El nombre genérico Ulota deriva del griego ulo (rizado), y se refiere a la forma en que las hojas se rizan y contorsionan cuando se secan. El nombre específico phyllantha deriva de los términos griegos phyllon

Ulota phyllantha Brid. (hoja) y anthēs (floración, florecido), y se refiere al grupo de estructuras clonares, que son percibidas como parecidas a flores, en la punta de las hojas. Estas pequeñas estructuras clonales son dispersadas fácilmente, permitiendo a la planta colonizar nuevas áreas sin necesidad de reproducción sexual. 
en sus dimensiones biofísicas como simbólicolingüística-culturales. A partir de esta integración, genera nuevas relaciones entre humanos y briófitas a través de tres pasos interrelacionados:

1) Construir desde la relación antagónica entre cercanía y distancia generada por la lupa misma, cuya presencia se prolonga a través del dibujo y los nombres dados. Por un lado, la lupa y el acto de dibujar y nombrar demandan una consideración más cercana y una interpretación artística que mueve a los visitantes a una proximidad íntima con las briófitas, instando el movimiento del cuerpo, la cara y las manos para una relación cercana con los musgos, hepáticas, antocerotes y líquenes. Por otro lado, la lupa sirve como un lente físico, un cristal que se interpone en el encuentro del visitante y las briófitas. A su vez, esta interposición física ayuda a los visitantes a entender la diversidad de lentes conceptuales -económico, biológico, biocultural, estético, discursivo, ético- que análogamente son intermediarios en nuestras relaciones con briófitas y líquenes. El acto de la interpretación artística, ya sea por dibujar como por nombrar, complementa el carácter simbólico de la lupa y fomenta la visibilidad de los lentes conceptuales a través de los cuales llegamos a ver las briófitas.

2) Presentar múltiples nombres científicos y comunes para especies de briófitas y líquenes en el Parque Omora a través de señaléticas y pequeñas discusiones dirigidas por el equipo. La Tabla 1 presenta una selección de nombres científicos de las especies de briófitas más comunes en el Parque Omora, con etimologías interpretadas que pueden ser utilizadas por las personas que guían esta actividad. Las señaléticas en el Parque Omora usualmente presentan para cada especie nombres comunes en yagán, español e inglés, junto con su nombre científico en latín. Al dirigir la atención hacia la multiplicidad de nombres, los visitantes pueden comenzar a ver las briófitas en el parque no como seres estáticos que han sido nombrados y que son tratados como objetos para ser recolectados (Dickinson, 2013), sino como seres vivos que están involucrados con y son interpelados por, una variedad de diferentes grupos culturales.

3) Cambiar la atención de una visión estática de los nombres hacia un proceso dinámico de cultivar nuevos nombres que son inestables, construidos, sociales y deliberados. Este proceso continuo e iterativo de "nombrar", que sigue a la observación y al compromiso, se vuelve mucho más importante que el establecimiento formal de un nombre en una especie en particular, lo cual solo requiere la mención del nombre "correcto". Nombrar se torna una práctica deliberativa a través de la cual se crean relaciones y se establecen significados, menoscabados y creados de nuevo. Mientras que un nombre - científico o común - es una entidad estable, el énfasis en cultivar como proceso insta a los visitantes a involucrarse constantemente con ( $y$ a) reconsiderar los seres pequeños a su alrededor y sus relaciones con ellos.

La actividad Cultivando un Jardín de Nombres cambia los lentes conceptuales de los visitantes desde enfocarse únicamente en los nombres científicos hacia motivarse a entender mejor y valorar la multiplicidad de nombres. Estos diversos nombres -y de lentes- asociados a diferentes culturas, incluyen aquellos que los mismos visitantes han creado a través de sus propios lentes culturales. Sería engañoso dar la impresión de que esta actividad estimula a participantes, individualmente, a inventar nombres aisladamente de sus tradiciones lingüísticas y culturales y sus contextos sociales. Durante la actividad, cuando los nombres inventados por los participantes son comparados y contrastados con los nombres dados para la misma especie por otros participantes, así como también con nombres conocidos provenientes de diferentes tradiciones culturales, incluyendo la cultura científica occidental (Tabla 1), los visitantes descubren nuevas características de las briófitas y también nuevas facetas de sus propios lentes culturales (a través de los cuales observan y valoran lo que observan). Esta comprensión biocultural promueve el descubrimiento y creación de relaciones más flexibles, dinámicas e imaginativas entre humanos y briófitas y líquenes que promueven la extensión de la ética más allá de la dimensión humana.

La actividad interactiva de dibujar, nombrar 
y discutir va más allá de simplemente presentar a los visitantes una serie de nombres científicos a lo largo de un sendero interpretativo. En ésta, se utiliza el poder de nombrar como una herramienta para conectar a las personas con la naturaleza, al mismo tiempo que evade la perpetuación de la desconexión entre humano y naturaleza, cuando se enfatiza sólo la entrega unidireccional de información (Dickinson, 2013). Nuestro propósito es, en cambio, motivar una comprensión dialéctica especie-ecológica (Milstein, 2011), que puede encontrarse en la interpretación de algunos nombres de musgos en lenguas amerindias, como el Mapudungun (de la cultura Mapuche; ver más adelante) y también en algunos nombres científicos occidentales. Por ejemplo, el briólogo suizo-germano Samuel Élisée von Bridel en 1827 nombró el género de musgos Philonotis [philos (amante) + notis (humedad)] por su preferencia por ambientes húmedos. Esta forma dialéctica de nombrar converge con el concepto central de la ética biocultural: los vínculos entre los hábitos, los hábitats y los co-habitantes. A través de este lente biocultural los estudiantes y otros visitantes exploran los dominios simbólico-lingüísticoculturales de nombres y conceptos, que invitan a cultivar formas de cohabitación interespecífica $e$ intercultural más respetuosas.

\section{LA BASE TEÓRICA PARA CULTIVAR UN JARDÍN DE NOMBRES}

\section{Briófitas como seres poco percibidos}

En esta sección describimos la integración del marco teórico de la FILAC y la ética biocultural con otros conceptos filosóficos: centrismo y otredad (Plumwood, 1999), la crítica del encasillamiento científico (Dickinson, 2013), la noción de pantallas terminológicas (Burke, 1966), los marcos mentales (Lakoff, 2010) y la actividad de señalar y nombrar (Milstein, 2011). Esta integración provee un marco filosófico amplio que posiciona el nombrar como una actividad relevante para mejorar la visualización de la diversidad de briófitas y líquenes, en su dimensión biofísica y valórica, y fomenta la empatía y el compromiso con estos seres poco percibidos.

Fuera del campo científico dedicado al estudio de las briófitas (i.e., briología), una gran diversidad de especies es normalmente subsumida por el concepto bioculturalmente homogeneizador "musgo", más que representado por una variedad de nombres comunes específicos. Sin embargo, las briófitas son excepcionalmente diversas, con un estimado de 18.000 a 20.000 especies de musgos, hepáticas y antocerotes (Vanderpoorten \& Goffinet, 2009). La invisibilidad de las briófitas en el lenguaje común resulta, en parte, del fuerte énfasis de la cultura occidental en el lente económico, que tiene su foco en el uso y valor de intercambio, lo cual tiende a fijarse en dimensiones particulares de la biodiversidad. Por ejemplo la palabra vernacular en inglés woodland reduce la diversidad que comprenden los bosques, casi literalmente a un área de tierra (land) que produce madera (wood) (Rozzi, 2015b). A través de un lente económico, los bosques (woodland) son valorados porque están compuestos por plantas "vasculares" que producen un bien: la madera, que está formada por células lignificadas que constituyen tejidos especializados en el transporte de agua y nutrientes. La subvaloración de las briófitas se evidencia en el lenguaje utilizado para su clasificación y nominación botánica, que implica una simplificación y una negación. Las briófitas usualmente son clasificadas como plantas "no-vasculares". Es decir, se definen por la ausencia de tejidos vasculares $y$, en consecuencia, quedan subordinadas a las plantas vasculares. Este lenguaje perverso de "plantas no-vasculares" no reconoce los atributos sofisticados de las briófitas, las cuales mueven agua y nutrientes a través de otros procesos o tejidos especializados (Vanderpoorten \& Goffinet, 2009).

El enfoque en tejidos vasculares y el valor económico de los bosques genera una yuxtaposición de briófitas sin valor y plantas vasculares con valor. Esta dicotomía se alinea con el concepto de Val Plumwood (1999) de "centrismo", al que ella se refiere como "un marco de ceguera moral y cultural" (p. 94). Aquí extendemos la categorización de Plumwood para incluir ceguera biocultural. Para la filósofa y ecofeminista australiana, los "centrismos hegemónicos dependen de la otredad" (Plumwood, 1999, p. 82), un proceso que hace que el centro parezca universal. Las briófitas ofrecen un ejemplo representativo; han sido definidas como el "otro" en relación a las 
hegemónicas plantas vasculares. Proponemos que un lente económico reduccionista genera "puntos ciegos" en la percepción de la biodiversidad. Estos puntos ciegos dificultan apreciar otros grupos de organismos, como briófitas y líquenes, así como también otros sistemas de valores que caen fuera de la visión económica dominante.

El programa de FILAC del Parque Omora, en la cumbre austral del planeta, arroja una luz que permite visualizar mejor la hegemonía del centrismo de las plantas vasculares económicamente valorables y la otredad de las briófitas. También permite comprender mejor el centrismo que representan los ecosistemas del Hemisferio Norte y la otredad de los ecosistemas del Hemisferio Sur en la investigación científica y en la cultura moderna. En la Reserva de la Biosfera Cabo de Hornos, el paisaje rico en briófitas comienza a ser visto como sobresaliente. Esta visión emergente del punto más austral de América contrasta con las narrativas dominantes originadas en paisajes europeos ricos en bosques, que han contribuido a posicionar a las briófitas como "otros-que-vasculares" o deficientes. Un sesgo marcado hacia narrativas científicas generadas desde paisajes europeos con abundantes bosques, y más ampliamente paisajes boreales templados, es muy evidente en la investigación ecológica a largo plazo de la actualidad. Más del 90\% de los sitios de estudios ecológicos a largo plazo y publicaciones científicas asociadas a ellos se originan en las regiones templado-boreales ( $\mathrm{Li}$ et al. 2015), expresando el marcado centrismo del Hemisferio Norte.

El filósofo australiano Arran Gare (1998) y el padre de la ética ambiental de los Estados Unidos, Aldo Leopold (1949) critican las consecuencias éticas de la narrativa económica dominante. Su dominación implica una omisión de un mayor espectro de valores, que implica que la mayoría de los seres vivos carecen de valor para la sociedad global. Más radicalmente, la cultura occidental globalizada carece de una ética ambiental. El estrecho enfoque en el lente económico está íntimamente asociado a una narrativa eurocéntrica ${ }^{5}$ colonial que prevalece hoy en la sociedad global. Esta narrativa centrada

5 Rozzi (2015a) señala que no es el Homo sapiens, en general, el responsable del consumo excesivo y la relegación de la naturaleza no-humana como "recursos naturales", sino más bien un determinado grupo de seres humanos en el capital, y su sistema de valorización asociado, resulta en una naturaleza vista como material de consumo o recurso natural, donde las briófitas y líquenes son vistos como "otros" y "menos que" por una relativa falta de valor económico.

Investigación científica de la evolución de las briófitas contradice su estigmatización como "Otredad"

La estructura de la Otredad esbozada por Plumwood (1999) es evidente en la homogeneización del lenguaje dualista utilizado durante el siglo XX en la investigación y la educación para describir las briófitas en relación con otros grupos de plantas en un contexto evolutivo. Además de ser definidas por una ausencia o por la distancia del centro dominante (Plumwood, 1999), las briófitas existentes han sido retratadas en las narrativas científicas de la evolución de las plantas de la tierra como "tempranas", "inferiores", o parientes "primitivas" de las plantas vasculares - y más marcadamente de las plantas con flor, o plantas "superiores". Esta perspectiva centrada en las plantas vasculares es incompatible con las recientes estimaciones científicas del tiempo de divergencia evolutiva (es decir, la edad de los grupos de especies, en este caso). Los estudios científicos más recientes sugieren que las briofitas no representan organismos evolutivamente primitivos, sino que la mayoría de los linajes existentes de briófitas surgieron al mismo tiempo o incluso después que los linajes de plantas vasculares, incluyendo las pantas con flor (Feldberg et al. 2014; Fiz-Palacios et al. 2011; Heinrichs et al. 2009; Laenen et al. 2014; Villarreal \& Renner, 2014). Por lo tanto, aunque las briófitas actuales son descendientes de hepáticas, musgos o antocerotes ancestrales, las especies actuales se encuentran en un proceso de continua de evolución y no constituyen "fósiles vivientes" o meras reliquias de ensambles de especies que existieron en la tierra hace 500 millones de años (Clarke et al. 2011). Adjetivos tales como "inferior", "temprano", o "primitivo" invocan un paradigma de estancamiento evolutivo

que mantienen una cantidad desproporcionada de riquezas y por lo tanto de poder dado el sistema plutocrático de los países occidentalizados. 
(Crum, 1972) ${ }^{6}$ que no está respaldado por datos filogenéticos moleculares modernos. En este marco, que fue dominante durante el siglo $\mathrm{XX}$, las briófitas que habitan actualmente el planeta, se presentan distorsionadamente como reliquias pasivas del pasado.

En la Reserva de la Biosfera Cabo de Hornos, la historia filogeográfica del musgo del estiércol Tetraplodon fuegianus, endémico de la ecorregión subantártica de Magallanes, desafía la obsoleta perspectiva científica del siglo XX sobre briófitas. T. fuegianus aporta un claro ejemplo de procesos evolutivos recientes. Durante el enfriamiento climático del Mioceno y las oscilaciones glaciales del Pleistoceno, los ámbitos de distribución de las especies cambiaron marcadamente en las altas latitudes de los hemisferios Sur y Norte (Sersic et al. 2011; Shafer et al. 2010). Durante este tiempo, un Tetraplodon del noroeste de América del Norte logró dispersarse probablemente en las plumas de aves migratorias (Lewis et al. 2014) hacia el otro extremo del continente y establecerse en la eco región sub-antártica de Magallanes (Lewis et al. 2014). Después de este evento de dispersión hace unos 8,6 millones de años $^{7}$, el Tetraplodon magallánico se aisló de las poblaciones en el hemisferio norte, acumulando variabilidad regional a medida que avanzaba a lo largo de una nueva trayectoria evolutiva (Lewis et al. 2016). Esta comprensión de su trayectoria evolutiva se manifiesta en su clasificación actual como una especie endémica, y en su nombre científico $T$. fuegianus, otorgado por el briólogo francés Émile Bescherelle (1885) por habitar en la región fueguina austral de Sud América, lejos de las poblaciones del noroeste de Norteamérica de T. mnioides. El análisis de las representaciones lingüísticas a la luz de la evidencia filogenética molecular reciente demuestra que es necesario ajustar los lentes conceptuales a través de los

6 Tradicionalmente, las distribuciones geográficas globales de las briófitas se han explicado como el resultado de procesos antiguos tales como la deriva continental, basada en la homogeneidad morfológica a través de amplios rangos intercontinentales junto con la suposición de que las especies de briófitas pertenecen a linajes antiguos (Herzog 1926; Schuster 1969). Crum (1972) sugirió que a partir de estas líneas de argumentación, las briófitas estarian evolutivamente estancadas, sin atravesar procesos de especiación debido al aislamiento de poblaciones distintas, cuales las briófitas son percibidas, retratadas, y en consecuencia, valoradas.

\section{El complejo papel de los nombres y del} acto de nombrar para hacer visible la diversidad poco percibida

La reciente investigación evolutiva basada en análisis moleculares proporciona evidencia crucial que contrarresta el lenguaje engañoso de los siglos XIX y XX que describió a las briófitas como "inferiores", "primitivas" o "tempranas". Aunque la evolución de estos organismos atrae la atención de briólogos, la visibilidad de las briófitas rara vez se extiende más allá de los límites de esta comunidad científica especializada.

Parece poco probable que la mera existencia de estudios evolutivos recientes basados en técnicas especializadas publicados en revistas científicas (como es el caso de Tetraplodon fuegianus, que socava las convenciones científicas lingüísticas dominantes del siglo $\mathrm{XX}$ ) ayuden a desencadenar un cambio de paradigma para una apreciación cultural más amplia de las briófitas. Tampoco lo desencadenará un amplio catálogo de nombres científicos. En medio del Antropoceno, que se caracteriza por el rápido aumento de una homogeneización biocultural mundial, se requiere una ética biocultural que pueda fomentarse con la aplicación de métodos como la FILAC (Rozzi, 2013, 2015a). Para enfrentar este reto, es útil considerar los nombres científicos como "pantallas terminológicas" del pensador y crítico literario estadounidense Kenneth Burke o "marcos mentales" del lingüista estadounidense George Lakoff. Al igual que Rozzi, en su análisis desde el marco conceptual de la ética biocultural, llama la atención respecto al énfasis en el valor económico dado por el término inglés woodland al bosque (Rozzi, 2015b). Burke (1966) y Lakoff (2010)

a pesar del paso de grandes períodos de tiempo y los grandes obstáculos para el flujo génico.

7 Las briófitas representan los linajes más antiguos entre las plantas terrestres existentes, que datan de hace más de 450 millones de años (durante el período Ordovícico). Por lo tanto, 8 millones de años atrás es un tiempo muy reciente para la evolución de briófitas, ya que representa menos del $3 \%$ del tiempo desde que briófitas ancestrales colonizaron la tierra. 
subrayan que las pantallas terminológicas y los marcos mentales ayudan a filtrar, es decir, eliminar y enfatizar posibilidades y perspectivas para comprender y valorar la realidad.

Las pantallas terminológicas o marcos mentales enfocan nuestra comprensión del mundo que nos rodea, entrenando nuestras mentes hacia ciertas interpretaciones, al mismo tiempo que nos aleja de otras. Los marcos operan de manera similar al papel desempeñado por los lentes conceptuales del Ecoturismo con lupa propuestos por Rozzi y colaboradores (2012b). Cuando se utilizan nombres científicos, éstos sirven como pantallas terminológicas o marcos mentales para apreciar los atributos biofísicos y para posicionar las especies de briófitas como organismos que poseen un valor científico, que son dignas de observación, estudio y catalogación, pero no necesariamente de encuentro, consideración e identificación de ellos como compañeros vivos o co-habitantes. Otras formas de lenguaje, como los nombres e historias amerindias (Kimmerer, 2003) y el lenguaje metafórico (Rozzi et al. 1998), complementan el lenguaje científico enmarcando a las briófitas como culturalmente relevantes, más allá de la cultura científica. Un conjunto de idiomas, en lugar de una sola lengua, es más apropiado para promover una mayor comprensión y valoración de las briófitas, e inspirar las relaciones éticas entre una diversidad de seres humanos y plantas pequeñas.

Basándose en su trabajo de comunicación ecocultural, Elizabeth Dickinson (2013) sostiene que la ciencia por sí sola no es un medio eficaz para promover conexiones entre los seres humanos y los no-humanos. Dickinson (2013) proporciona una importante crítica del "encuadre de la ciencia", puesto que el acto de educar a la gente de una manera puramente científica para estimular el interés por la naturaleza, acaba teniendo un efecto negativo en el desarrollo de una conexión entre las personas y la "naturaleza". El excesivo énfasis en el enfoque analítico y cognitivo, que ignora lo emocional, desconecta emocionalmente a la gente de la naturaleza.

Dickinson (2013) propone mirar más allá del enfoque de meramente nombrar especies individuales. Advierte que el uso de nombres científicos en programas de ecoturismo $y$ educación (a lo que habría que añadir el excesivo énfasis relacionado únicamente con los "hechos" válidos de una investigación) puede resultar en una "colección de nombres" y catalogación de la naturaleza. Este énfasis cientificista fomenta una relación donde las plantas y los animales son objeto de conquista, en lugar de sujetos en su propio derecho, o en los términos de la perspectiva de la ética biocultural (Rozzi, 2015a), co-habitantes que deben ser considerados en las deliberaciones de un futuro colectivo. Para fomentar relaciones de co-habitar con sujetos no-humanos como propone la ética biocultural, el argumento Dickinson (2013) es relevante puesto que aconseja "no nombrar" en los primeros encuentros con estos sujetos, y favorecer en cambio experiencias interactivas. De esta manera, el acto de nombrar se genera desde las perspectivas de los visitantes, permitiendo que las personas se conecten en sus propios términos (individuales y de sus tradiciones culturales), más que sólo en los de la cultura de la ciencia occidental.

Vemos el valor en la perspectiva de Dickinson (2013), y en nuestra actividad Cultivando un Jardín de Nombres ofrecemos una corrección a la tendencia de querer registrar y fijar solo los nombres científicos. Para ello registramos también los nombres vernáculos de briófitas (Lavoie, 2012, 2014) y líquenes (Goward et al. 1994), como también los compuestos por los visitantes. Esta actividad puede representar una iniciativa valiosa para re-inscribir la diversidad de nombres como visibles y valiosos. Presentar y comunicar nombres crea un espacio conceptual para que las briófitas existan en el dominio simbólico-lingüístico de la sociedad. La periodista e investigadora de comunicación ambiental Tema Oliveira Milstein (2011) ofrece un sólido ejemplo de este tipo de trabajo en su discusión de "señalar y nombrar" ballenas asesinas (orcas) en el Pacífico del noroeste de América del Norte y su rol en el fomento de las conexiones Humano-Naturaleza que conducen a las acciones de conservación. Milstein (2011, p.4) sugiere que:

Señalar y nombrar puede ser visto como una entrada básica para discernir y categorizar socialmente partes de la naturaleza. De esta manera, los actos de señalar y nombrar generan ciertos tipos de conocimiento ecocultural que 
constituyen aspectos de la naturaleza como es considerada; únicos, ordenados, o marcados.

El reconocimiento de individuos de ballenas asesinas tuvo un efecto beneficioso sobre la conservación y la valoración de las ballenas por los seres humanos. Sin embargo, en el análisis de Milstein, el método de señalar y nombrar estaba limitado a la hora de inculcar una ética similar hacia el ecosistema en su conjunto. Milstein (2011) sugiere que las personas que realicen las actividades ecoturísticas, eviten el enfoque en una sola especie o individuo nombrado, tejiendo historias de los sujetos en un contexto ecológico: la dialéctica ecológico-individuo. Con el marco conceptual de la ética biocultural (Rozzi 2012) esto se puede lograr mediante la vinculación de los co-habitantes y sus hábitos de vida con los hábitats que forman y que son moldeados por ellos.

\section{LA FILAC COMO BASE PARA UNA INTERACCIÓN RELACIONAL}

Los investigadores en el Parque Omora acogen un espíritu de interactividad dinámica, tal como propone Dickinson (2013). Mediante el diseño de experiencias lúdicas, de inmersión, se involucra a los visitantes con el fin de provocar interacciones relacionales que podrían conducir a una extensión de las consideraciones éticas para incluir a estos seres poco percibidos. Nombrar, dibujar, y generar narrativas anima a los visitantes a ampliar sus marcos conceptuales, tramas de términos e imaginarios para incluir cohabitantes que de otro modo son invisibles. De hecho, una de las primeras iniciativas de la FILAC trabajó en la ampliación del "imaginario florístico" de profesores y estudiantes de Puerto Williams que tenían la limitación de estar centrados en rosas y manzanos (que no crecen en la Reserva de Biosfera Cabo de Hornos), y eran ciegos a musgos y líquenes (Rozzi et al. 2008a).

Para transformar la realidad cultural, incluyendo los imaginarios florísticos de los ciudadanos, la FILAC integra la investigación filosófica, retórica y científica. Esta síntesis teórica se puso de manifiesto con la investigación sobre la historia evolutiva de Tetraplodon fuegianus, y la investigación de las etimologías de las especies de briófitas (Fig. 1 y Tabla 1). La investigación científica sobre $T$. fuegianus se centró en las dimensiones biofísicas, mientras que la investigación filosófica y etimológica se enfocó en dimensiones simbólicolingüísticas. La historia evolutiva de $T$. fuegianus resuena con la metáfora biofísica de los Bosques en Miniatura del Cabo de Hornos. La atención a las etimologías y al nombrar nos ha inspirado a crear la metáfora simbólico-lingüística del Bosque de Nombres. La metáfora del Bosque de Nombres (etapa 2 de la FILAC) lingüísticamente conecta los dominios biofísico (bosque) y simbólico-lingüístico (nombres).

La amalgama de investigaciones filosóficas, evolutivas, y etimológicas suscita la composición de metáforas en la FILAC, en este caso el Bosque simbólico-lingüístico de Nombres. El paso 3 de la FILAC se construye a partir tanto de la investigación como de las metáforas para crear actividades de campo guiadas con una orientación ecológica y ética. Este proceso nos lleva a crear la actividad Cultivando un Jardín de Nombres. Análogo al Bosque de Nombres, "Cultivar" también transmite un enlace entre los dominios biofísico y simbólicolingüístico. El término "cultura", de hecho, deriva de la palabra latina cultura, que originalmente significó cultivar la tierra (Rozzi, 2015a). Más tarde este concepto fue ampliado en la Europa moderna para ser utilizado en referencia a la educación y al cultivo del pensamiento. Además, el término arcaico "cultivar" indica que el concepto de cultura se asociaba originalmente con un verbo, con una praxis: "cultivar la tierra" y más tarde "cultivarse a través de la educación"; no se trata de un sustantivo o un objeto estático. Poéticamente, "cultivar" sugiere una integración del acto de "cultivar el jardín de musgos", al mismo tiempo que estamos "cultivándonos a nosotros mismos".

Para facilitar la actividad Cultivando un Jardín de Nombres y la integración deliberada de dominios biofísicos y simbólico-lingüísticos en el Parque Omora, hemos puesto en marcha una estación de interpretación específica a lo largo del sendero de los Bosques en Miniatura del Cabo de Hornos. Estamos preparando un folleto ilustrado para mejorar las experiencias guiadas con un amplio espacio para que los participantes puedan dibujar, tomar notas y registrar sus reflexiones. 
Nombrar: práctica deliberativa que revela y crea diversidad biocultural

Dentro del paradigma de la diversidad biocultural, la diversidad cultural y biológica se entrelazan dentro de un hábitat específico. Los nombres científicos y locales dados a las plantas reflejan aspectos esenciales tanto de las plantas nombradas como de las normas culturales y las experiencias de los grupos humanos que le dan el nombre . $^{2}$

Los nombres reflejan tanto la presencia biofísica como la cultural humana en el Bosque en Miniatura. Las culturas pueden presentar puntos de convergencia. Por ejemplo, el pueblo originario mapuche (gente [= che] de la tierra [= mapu]) habla mapudungún, la lengua (=dungun) de la tierra (= mapu). En esta lengua, el modo de nombrar a los seres humanos y no-humanos presenta una similitud notable con el concepto de las "3 Hs" de la ética biocultural. Respecto a los nombres dados a los musgos, el mapudungún tanto como la ética biocultural interrelacionan los hábitos de vida de las plantas con la comunidad de co-habitantes, y el hábitat donde crecen (Rozzi et al. 2012b). Una de las palabras en mapudungún para nombrar musgos es poñpoñ (Villagrán, 1998), especialmente aquellos que crecen en las turberas y bosques. Los mapuche también nombran los musgos en base a sus hábitos de vida y microhábitats: un musgo que crece en la piedra (por ejemplo, Racomitrium lanuginosum) se llama poñpoñ-kura (piedra = kura; musgo = ponpon) (Villagrán, 1998); un musgo que crece en la madera (por ejemplo, Hypnum chrysogaster) se llama poñpoñmämell (= madera) (Moesbach, 1936). Pequeños helechos del género Hymenophyllum que crecen en la madera se llaman mamëll tapëll es decir, las hojas (= tapëll) de madera (Villagrán, 1998).

Los nombres en mapudungun para algunos musgos también reflejan las interacciones ecológicas dentro de la comunidad de cohabitantes. Por ejemplo, Weymouthia orbiculata se llama pinda-poñpoñ o musgo colibrí (= pinda), ya que es utilizado por los colibríes para construir

8 Rozzi et al. (2008b) ilustran esto con el ejemplo del upush/ zarzaparrilla/Ribes magellanicum/wild currant, donde los diferentes nombres en yagán, español, ciencia occidental y sus nidos (Villagrán, 1998). Algunos nombres también incluyen interacciones humano-musgo. Por ejemplo, los musgos para los cuales se conocen propiedades medicinales se denominan poñpoñlawen (lawen $=$ medicina). Otras pequeñas plantas con propiedades medicinales reciben nombres análogos tales como el pequeño helecho Hymenophyllum dentatum llamada llushu-lawen (medicina para bebés = llushu); el pequeño helecho Elaphoglossum gayanum llamado mapulawen (medicina común de la tierra); y Lycopodium lycopodium paniculatum llamado llanca-lawen (medicina valiosa $=$ llanca) (Villagrán, 1998). Al nombrar co-habitantes en el bosque, observando su estilo de vida y la articulación entre los co-habitantes, los mapuche comunican detalles sobre la vida de la planta asociada con el hábitat y las relaciones ecológicas. El mapudungún probablemente incluía muchos otros nombres para las briófitas y líquenes; sin embargo se han perdido como consecuencia de siglos de opresión, desplazamiento y las limitaciones culturales que enfrenta el pueblo mapuche aún en la actualidad (Moesbach, 1936; Villagrán, 1998).

El marco de la ética biocultural denuncia que los seres que carecen de nombres son invisibles. La presencia o ausencia de nombres en una cultura determinada pueden hacer de algunos grupos no-humanos visibles a ésta, pero invisibles a otra cultura. Análogamente, la exclusión o ausencia de nombres para una cierta cultura, puede tornar a esa cultura invisible. Además de las limitaciones señaladas por Dickinson (2013) y Milstein (2011), un enfoque limitado a los nombres científicos de las briófitas nos da cuenta de la diversidad biocultural. Si solo se consideran nombres científicos, sólo la cultura científica occidental está representada en el dominio simbólico-lingüístico del Bosque en Miniatura. Nuestra actividad Cultivando un Jardin de Nombres tiene como objetivo hacer visible, valorar y conservar los co-habitantes en su diversidad biológica y cultural vinculada a la exuberante diversidad de briófitas y líquenes, sus nombres, valores y prácticas culturales asociadas, en el Cabo de Hornos y otras regiones del mundo.

cultura europea, respectivamente, revelan interpretaciones culturales e interacciones distintas con esta planta en particular. 


\section{El dinámico bosque simbólico-lingüístico}

Así como las relaciones ecológicas pueden ser vistas como una compleja red de cadenas entrelazadas en la diversidad biofísica (por ejemplo, la pirámide trófica descrita por Leopold en 1949); los nombres y los conceptos asociados a esta diversidad biofísica se entrelazan de manera análoga en la diversidad lingüística y cultural formando un bosque simbólico-lingüístico metafórico, que está estrechamente entrelazado con el Bosque en Miniatura biofísico. La expresión Bosque de Nombres nos ayuda a entender la interconexión de la diversidad cultural y biofísica. Al igual que la noción de "Rizoma" acuñada por los filósofos franceses Gilles Deleuze y Félix Guattari (1987), en la FILAC no hay principio ni fin, sino un flujo continuo de interrelaciones dentro y entre los dominios biofísicos y simbólico-lingüísticos. Creación y pérdida de nombres e ideas, o la distribución y la abundancia variable de co-habitantes biofísicos, genera un continuo cambio de interrelaciones en el bosque simbólico-lingüístico, un reflejo de los procesos ecológicos dinámicos que ocurren a lo largo de los Bosques en Miniatura.

La hepática Marchantia berteroana y el musgo del estiércol Tetraplodon fuegianus ilustran la dinámica ecológica y la naturaleza de las interrelaciones en los Bosques en Miniatura. Cuando se construyó el sendero de los Bosques en Miniatura, una estación en un claro de bosque asociado a una castorera tenía el suelo cubierto de Marchantia. Esta hepática es una especie pionera que coloniza sitios húmedos que han sido perturbados. La práctica de conservación en el Parque Omora ha sido erradicar los castores (Castor canadensis) que representan una especie exótica introducida desde Norteamérica a mediados del siglo XX y que ha generado un alto impacto en los ecosistemas subantárticos (Crego et al. 2016). Después de haber erradicado el castor, las hierbas y arbustos pequeños recolonizaron el área y han dominado el claro, y ahora $M$. berteroana está ausente. Otro caso de interacciones dinámicas se registra en el musgo del estiércol Tetraplodon fuegianus, cuya distribución depende de la interacción con animales. La red de interacciones asociadas a la presencia o la ausencia de estiércol o restos de animales en descomposición, las moscas que se posan sobre éstos y dispersan las esporas de Tetraplodon sobre sustratos ricos en nutrientes, influyen directamente sobre los patrones de distribución de este musgo en los Bosques en Miniatura (Koponen, 1990).

Respecto a los Bosques de Nombres, es crítico advertir que la diversidad simbólicolingüística se está perdiendo rápidamente a través de procesos de homogeneización biocultural (Rozzi, 2013). El acto de investigar, descubrir y crear nombres y compararlos con los nombres de diferentes tradiciones culturales ayuda a superar los puntos ciegos derivados de eurocentrismos valóricos y culturales. Cultivando un Jardín de Nombres no sólo ayuda a visibilizar mejor las briófitas y líquenes, sino también a apreciar mejor la diversidad de tradiciones culturales que habitan en los Bosques en Miniatura del Cabo de Hornos. Destacando el proceso de nombrar, más que el de aprender y establecer un nombre fijo para cada especie particular, la actividad Cultivando un Jardín de Nombres enfatiza la naturaleza dinámica y plural de los bosques simbólico-lingüísticos.

\section{CONCLUSIÓN}

Invitamos a investigadores de otras regiones del país y del mundo a considerar la posibilidad de jugar con actividades como la de Cultivar un Jardin de Nombres, que vinculan profundamente a seres humanos con seres no-humanos. Aunque esta actividad ha sido desarrollada en el Parque Omora, podría ser adaptada en otros sitios de investigación, conservación y/o educación. Esperamos colaborar con investigadores que trabajan conectando los dominios biofísicos y simbólicolingüísticos y en conjunto cultivar nuevos hábitos que permitan a los co-habitantes explorar sus profundas conexiones entre sí y sus hábitats. Este tipo de compromiso profundo es necesario para llegar a descubrir y crear relaciones más flexibles, dinámicas, informadas e imaginativas entre los seres humanos y seres poco percibidos, como briófitas y líquenes, que extienden la ética más allá del ámbito humano. 


\section{AGRADECIMIENTOS}

Los autores agradecen al equipo interdisciplinario e interinstitucional y a los voluntarios del Parque Etnobotánico Omora que se dedican a la conservación biocultural. Este trabajo solo ha sido posible gracias a las contribuciones de todos quienes han trabajado y continúan trabajando en el Parque Etnobotánico Omora. Paola Vezzani contribuyó significativamente al desarrollo y las pruebas en terreno de las secciones de dibujo y discusión de la actividad Cultivando un Jardín de Nombres. Agradecemos al Instituto de Ecología y Biodiversidad de Chile, el Fondo Nacional para la Ciencia de los Estados Unidos (NSF-GRFP a LRL), la Fundación Robert and Patricia Switzer (2013 Environmental Fellowship a LRL) y Trudy Gerlach por el apoyo financiero, y al Profesor Patricio Arce, de la Pontificia Universidad Católica de Chile, por facilitar recursos humanos y de laboratorio. El trabajo de BG en el Parque Omora fue parcialmente financiado por fondos DEB-1240045 y 1354631 de la NSF. Stuart McDaniel proveyó recursos claves en términos de tiempo y espacio que permitieron la finalización de este trabajo. La preparación de este artículo ha contado con el apoyo de los proyectos CONICYT PFB- 23 y Apoyo a Centros Científicos y Tecnológicos de Excelencia con Financiamiento Basal CONICYT AFB170008.

\section{BIBLIOGRAFÍA}

Adams, J., Faure, H., Faure-Denard, L., McGlade, J., \& Woodward, F. (1990). Increases in terrestrial carbon storage from the Last Glacial Maximum to the present. Nature, 348, 711-714.

Belyea, L. R., \& Malmer, N. (2004). Carbon sequestration in peatland: Patterns and mechanisms of response to climate change. Global Change Biology, 10(7), 10431052.

Bescherelle, E. (1885). Mousses nouvelles de l'Amérique australe. Bulletin de la Société Botanique de France, 32, 54-69.

Bonnet, X., Shine, R., \& Lourdais, O. (2002). Taxonomic chauvinism. Trends in Ecology \& Evolution, 17(1), 1-3.

Burke, K. (1966). Language as symbolic action: Essays on life, literature, and method. California, USA: University of California Press.
Clarke, J. T., Warnock, R. C. M., \& Donoghue, P. C. J. (2011). Establishing a time-scale for plant evolution. The New Phytologist, 192(1), 266-301.

Crego, R.D., J.E. Jiménez, R. Rozzi. (2016). A synergistc trio of invasive mammals? Facilitative interactions among beavers, muskrats, and mink at the world's southernmost forests. Biological Invasions 18: 19231938.

Crum, H. A. (1972). The geographic origins of the mosses of North America's eastern deciduous forest. Journal of the Hattori Botanical Laboratory, 35, 269-298.

Daniëls, F. J. A., Gillespie, L. J., Poulin, M., \& Al, E. (2013). Plants. In Meltofte, H. (ed.) 2013. In Arctic Biodiversity Assessment. Status and trends in Arctic biodiversity. Conservation of Arctic Flora and Fauna, Akureyri, Iceland, (pp. 310-353).

Deleuze, G., \& Guattari, F. (1987). A Thousand Plateaus: Capitalism and Schizophrenia. Minnesota, USA: University of Minnesota Press.

Dickinson, E. (2011). Displaced in nature: The cultural production of (non-)place in place-based forest conservation pedagogy. Environmental Communication, 5(3), 300-319.

Dickinson, E. (2013). The misdiagnosis: Rethinking "Naturedeficit Disorder". Environmental Communication, 7(3), 315-335.

Dixon, H. N., (1904). The Students Handbook of British Mosses. V.T. Sumfield, Station Street, Eastborne, UK.

Druschke, C. G., \& McGreavy, B. (2016). Why rhetoric matters for ecology. Frontiers in Ecology and the Environment, 14(1), 46-52.

Feldberg, K., Schneider, H., Stadler, T., Schäfer-Verwimp, A., Schmidt, A.R., \& Heinrichs, J. (2014). Epiphytic leafy liverworts diversified in angiosperm-dominated forests. Scientific reports, 4, 5974 .

Fiz-Palacios, O., Schneider, H., Heinrichs, J., \& Savolainen, V. (2011). Diversification of land plants: insights from a family-level phylogenetic analysis. BMC evolutionary biology, 11, 341.

Gare, A. (1998). MacIntyre, Narratives, and Environmental Ethics. Environmental Ethics, 20(1), 3-21.

Goffinet, B., Rozzi, R., Lewis, L., Buck, W., \& Massardo, F. (2012). Miniature Forests of Cape Horn: Ecotourism with a Hand Lens. Texas (TX), USA: University of North Texas Press.

Goward, T., McCune, B., \& Meidinger, D. (1994). The lichens of British Columbia: Illustrated Keys, Part 1 - Foliose and squamulose species. Victoria, B.C, Canada: Ministry of Forests Research Program. Retrieved from: 
https://www.for.gov.bc.ca/hfd/pubs/docs/srs/Srs08. pdf

Hall, C. M., James, M., \& Baird, T. (2011). Forests and trees as charismatic mega-flora: implications for heritage tourism and conservation. Journal of Heritage Tourism, 6(4), 309-323.

Heinrichs, J., Hentschel, J., Feldberg, K., Bombosch, A., \& Schneider, H. (2009). Phylogenetic biogeography and taxonomy of disjunctly distributed bryophytes. Journal of Systematics and Evolution, 47(5), 497-508.

Herzog, T. (1926). Geographie der Moose. Jena, Alemania: Gustav Fischer.

Koponen, A. (1990). Entomophily in the Splachnaceae. Botanical Journal of the Linnean Society, 104, 115127.

Kimmerer, R. W. (2003) Gathering moss: a natural and cultural history of mosses. Oregon, USA: Oregon State University Press.

Laenen, B., Shaw, B., Schneider, H., Goffinet, B., Paradis, E., Désamoré, A., ... Shaw, A. J. (2014). Extant diversity of bryophytes emerged from successive post-Mesozoic diversification bursts. Nature Communications, 5, 6134.

Lakoff, G. (2010). Why it matters how we frame the environment. Environmental Communication: A Journal of Nature and Culture, 4(1), 70-81.

Lavoie, A. (2012). Les noms français des bryophytes du QuébecLabrador, Canada: anthocérotes et hépatiques. Carnets de Bryologie. Carnets de Bryologie, 2, 1-11.

Lavoie, A. (2014). Les noms français des bryophytes du QuébecLabrador, Canada : mousses. Carnets de Bryologie, 6, $1-17$.

Leopold, A. (1949). A Sand County Almanac and Sketches Here and There. New York, USA: Oxford University ress.

Leopold, C. (2004). Living with the Land Ethic. BioScience, 54, 149-154.

Lewis, L. R., Behling, E., Gousse, H., Qian, E., Elphick, C. S., Lamarre, J.-F., ... Goffinet, B. (2014). First evidence of bryophyte diaspores in the plumage of transequatorial migrant birds. PeerJ, 2, e424.

Lewis, L. R., Liu, Y., Rozzi, R., \& Goffinet, B. (2016). Infraspecific variation within and across complete organellar genomes and nuclear ribosomal repeats in a moss. Molecular Phylogenetics and Evolution, 96, 195-199.

Li, B., Parr, T., \& Rozzi, R. (2015). Geographical and thematic distribution of publications generated at the International Long-Term Ecological Research Network
(ILTER) Sites. In R. Rozzi, F. S. Chapin, J. B. Callicott, S. T. A. Pickett, M. E. Power, J. J. Armesto \& R. H. May Jr. (Eds.), Earth Stewardship: Linking Ecology and Ethics in Theory and Practice (2nd ed., pp. 195216). Switzerland.

Lindo, Z., \& Gonzalez, A. (2010). The bryosphere : An integral and influential component of the earth's biosphere. Ecosystems, 13, 612-627.

Lindo, Z., Nilsson, M. C., \& Gundale, M. J. (2013). Bryophytecyanobacteria associations as regulators of the northern latitude carbon balance in response to global change. Global Change Biology, 19, 2022-2035.

Mateo, R. G., Broennimann, O., Normand, S., Petitpierre, B., Araújo, M. B., Svenning, J. C., ... Vanderpoorten, A. (2016). The mossy north: an inverse latitudinal diversity gradient in European bryophytes. Scientific Reports, 6(April), 25546.

Milstein, T. (2011). Nature identification: The power of pointing and naming. Environmental Communication, 5(1), 3-24

Moesbach, W. (1936). Vida y costumbres de los indigenas araucanos en la segunda mitad del siglo XIX. Santiago, Chile: Imprenta Universitaria.

Naess, A. (1973). The shallow and the deep, long-range ecology movement. A summary. Inquiry: An Interdisciplinary Journal of Philosophy, 16(1-4), 95-100.

Ochyra, R., Smith, L., \& Bednarek-Ochyra, H. (2008). The Illustrated Moss Flora of Antarctica. New York, USA: Cambridge University Press.

Plumwood, V. (1999). Paths beyond human-centeredness. In A. Weston (Ed.), An Invitation to Environmental Philosophy (pp. 69-105). New York, USA: Oxford University Press.

Rozzi, R. (2012). Biocultural ethics: Recovering the vital links between the inhabitants, their habits, and habitats. Environmental Ethics, 34, 27-50.

Rozzi, R. (2013). Biocultural ethics: From biocultural homogenization toward biocultural conservation. In Linking Ecology and Ethics for a Changing World: Values, Philosophy, and Action, eds. R. Rozzi, S.T.A. Pickett, C. Palmer, J.J. Armesto \& J.B. Callicott, pp. 9-32. Dordrecht, Netherlands: Springer.

Rozzi, R. (2015a). Implications of the biocultural ethic for earth stewardship. In R. Rozzi, F. S. I. Chapin, J. B. Callicott, S. T. A. Pickett, M. E. Power, J. J. Armesto, \& R. H. May (Eds.), Earth Stewardship: Linking Ecology and Ethics in Theory and Practice (2nd ed., pp. 113-136). Dordrecht, Netherlands: Springer.

Rozzi, R. (2015b). Earth stewardship and the biocultural ethic: 
Latin American perspectives. In R. Rozzi, F. S. I. Chapin, J. B. Callicott, S. T. A. Pickett, M. E. Power, J. J. Armesto, \& R. H. May (Eds.), Earth Stewardship: Linking Ecology and Ethics in Theory and Practice (2nd ed., pp. 87-112). Dordrecht, Netherlands: Springer.

Rozzi, R., E. Hargrove, J.J. Armesto, S.T.A. Pickett, J. Silander. (1998). "Natural drift" as a post-modern metaphor. Revista Chilena de Historia Natural, 71, 9-21.

Rozzi, R., Armesto, J., Goffinet, B., Buck, W., Massardo, F., Silander, J.,... Callicott, J. (2008a). Changing lenses to assess biodiversity: patterns of species richness in sub-Antarctic plants and implications for global conservation. Frontiers in Ecology and the Environment, 6(3), 131-137.

Rozzi, R., Arango, X., Massardo, F., Anderson, C., Heidinger, K., \& Moses, K. (2008b). Field environmental philosophy and biocultural conservation: The Omora Ethnobotanical Park educational program. Environmental Ethics, 30, 325-336.

Rozzi, R., Anderson, C., Pizarro, J., Massardo, F., Medina, Y., Mansilla, A., ... Kalin, M. (2010). Field environmental philosophy and biocultural conservation at the Omora Ethnobotanical Park: Methodological approaches to broaden the ways of integrating. Revista Chilena de Historia Natura, 83, 27 - 68.

Rozzi, R., Armesto, J., Gutiérrez, J., Massardo, F., Likens, G., Anderson, C., ... Arroyo, M. (2012a). Integrating Ecology and Environmental Ethics: Earth Stewardship in the Southern End of the Americas. BioScience, 62(3), 226-236.

Rozzi, R., Lewis, L., Massardo, F., Medina, Y., Moses, K., Mendez, M., ... Goffinet, B. (2012b). Ecotourism with a Hand Lens at Omora Park. Ediciones Universidad de Magallanes.

Schuster, R. M. (1969). Problems of antipodal distribution in lower land plants. Taxon, 18, 46-91.

Sérsic, A. N., Cosacov, A., Cocucci, A. A., Johnson, L. A., Pozner, R., Avila, L. J., ... Morando, M. (2011). Emerging phylogeographical patterns of plants and terrestrial vertebrates from Patagonia. Biological Journal of the Linnean Society, 103(2), 475-494.

Shafer, A. B., Cullingham, C. I., Côté, S. D., \& Coltman, D. W. (2010). Of glaciers and refugia: A decade of study sheds new light on the phylogeography of northwestern North America. Molecular Ecology, $19,4589-4621$

Small, E. (2012). The new Noah's Ark: beautiful and useful species only. Part 2. The chosen species. Biodiversity, 13(1), 37-53.

Vanderpoorten, A., \& Goffinet, B. (2009). Introduction to Bryology. Cambridge, UK: Cambridge University Press.

Villagrán, C. (1998). Indigenous ethnobotany of Chilean forests: classification system of a multiple-use resource. Revista Chilena de Historia Natural, 71, 245-268.

Villarreal, J. C., \& Renner, S. S. (2014). A review of molecular-clock calibrations and substitution rates in liverworts, mosses, and hornworts, and a timeframe for a taxonomically cleaned-up genus Nothoceros. Molecular Phylogenetics and Evolution, 78(1), 2535.

Webster. (2002). Dictionary of Prefixes, Suffixes, and Combining Forms from Webster's Third New International Dictionary Unabridged (https://secure.spellingbee. com/forms/M_W_pre_suf_comb.pdf). 
